\title{
A PROPOSED SAFETY COEFFICIENT FOR FLEXIBLE PAVEMENT DESIGN IN AFGHANISTAN
}

\author{
Mohammad Razeq Shakhan ${ }^{1}$ \\ ${ }^{1}$ Department of Civil Engineering, Dokuz Eylul University, Cumhuriyet Bulvarı No: 14435210 \\ Alsancak/Izmir, Turkey
}

Received 21 June 2021; accepted 22 August 2021

\begin{abstract}
The conventional AASHTO pavement design methods were developed for specific climate conditions in the United States of America, which significantly limits its ability to consider the climate conditions in other parts of the world. As the environmental factors have a strong effect on pavement performance, therefore, the performance of pavements designed according to AASHTO 1993 and constructed in different zones would not be the same. In other words, the pavement structure would be over or under-designed, when AASHTO 1993 is used. In contrast, the climate effects are widely considered in the Mechanistic-Empirical (ME) pavement design method. Although Afghanistan consists of extremely different climatic zones, still flexible pavements are designed based on AASHTO 1993 method. Therefore, this study investigates the temperature effect on flexible pavement distresses in hot and cold regions in Afghanistan in order to optimize the AASHTO 1993 using the mechanisticempirical approach. Thus, a typical flexible pavement was designed using AASHTO 1993 for three traffic levels [5, 20, and 50 Equivalent Single Axle Load (ESAL)] and then, the designed pavement structures were simulated by ME pavement design software to predict the rutting and cracking. Results revealed that AASHTO 1993 designs thinner pavement layers in the hot region which is reflected in the prevalent rutting problem in the hot region in Afghanistan. Furthermore, based on analysis results, a conservative design based on the ME pavement design analysis is recommended to be used to scale up the pavement thickness.
\end{abstract}

Keywords: AASHTO 1993, pavement design, alligator cracking, rutting.

\section{Introduction}

Afghanistan and many other developing countries have been utlized the empirical AASHTO pavement design method (19621993) to determine the required pavement layers thiknesses. These conventional methods are greatly limited by the original test conditions such as one subgrade type, one type of asphalt mixture, one climate zone, tire pressure, two million traffic repetitions, and a 2 -year test only. These restrictions can be underlined as drawbacks of this method. If the original test conditions are not applied, the pavement design may cause an over or under-design. Therefor, and in order to alleviate the cons of the traditional AASHTO Pavement Design Method, the Mechanistic-Empirical Pavement Design Guide (MEPDG) was emerged in 2004 by the AASHTO Joint Task Force and the National Cooperative Highway Research Program (NCHRP). In this method, the pavement responses (stresses and strains) are calculated

${ }^{1}$ Corresponding author: razeq.shakhan@ogr.deu.edu.tr 
and the pavement distresses (rutting, and cracking as well as international roughness index (IRI)) are predicted. The MEPDG utizes the historical climate data (e.g., hourly temperature, hourly sunshine, hourly wind speed, hourly humidity and hourly precipitation) as design input parameter to deem and estimate the environment effects on the pavement performance. The MEPDG proposes that climate data would be collected equal to the pavement design life (AASHTO, 2020). After the development of this method lots of researches were conducted in different countries to determine the impact of design factors based on local conditions (Shakhan et al., 2019).

Carvalho and Schwartz carried out a comparative study between AASHTO 1993 and MEPDG to evaluate the MEPDG. They selected and designed a typical threelayer flexible pavement based on AASHTO 1993 and then the ME pavement design method software was used to simulate the designed pavement sections and predict the pavement performances (e.g., rutting and fatigue cracking). The design was done for different climate zones in the USA at three reliabilities levels (85\%, 90\%, and 95\%). The study results showed that AASHTO 1993 under-estimates in warm areas and for high traffic repetition compared to the ME pavement design method predicted distresses (Carvalho and Schwartz, 2006).

Another study which were done in Kansas State University in the USA show that AASHTO 1993 would over-estimates the flexible pavement structure comparing to the MEPDG (Mulandi et al., 2006).

The AASHTO 1993 and MEPDG was compared using local design inputs (climate condition, traffic characteristics, and materials) in Iran. In this study, MEPDG software was used for redesigning the five previously constructed flexible pavement sections that had been designed by the empirical AASHTO method. The result showed that the empirical AASHTO method overestimates the AC layer thickness when compared to the MEPDG design output (Amini and Behbahani, 2011).

The effect of environmenal condition on pavement performance was carried out in Canda. The study results show rutting and Interantional Roughness Index (IRI) are sensitive to climate changes. It was also found that differences in the quality and duration of data for close-by stations can result in variation in the predicted performance (Saha et al., 2014).

In another case study, a typical flexible pavement structure was design using AASHTO 1993 for two different traffic volumes and two subgrade types (weak and strong) to consider the effect of Egyptian climate on flexible pavement performance. The pavement designed sections were simulated using MEPDG software to predict the pavement performance (rutting and cracking). The results show AASHTO 1993 under-estimates the pavement structure when traffic level is high for any climate condition (El-Shaib et al., 2017).

In a case study, the Idaho Pavement Design Procedure, AASHTO 1993, and MEPDG methods were compared to find out the effect of local condition including climate effects on pavement performance. Therefore, a typical two-layer pavement structure (AC surface and granular base) were selected that had been designed for 20 -year. The study result shown that there is not significant difference between AASHTO 1993 and 
MEPDG. But, the Idaho Transportation Department (ITD) pavement design method scientifically overestimates the pavement structure when compared whit AASHTO 1993 and MEPDG (El-Badawy et al., 2011).

After the establishing of new government in Afghanistan in 2002, hundreds of kilometers of flexible pavements were designed and constructed based on AASHTO 1993 method. Special Inspector General for Afghanistan Reconstruction (SIGAR) performed a road condition survey in Afghansitan in 2016. They rated the condition of each road segment as bad (road is not driveble), fair (road has many minor damages and few major damages which making driveability difficult), good (road has many minor damges), or very good (road has few minor damges). They found that, out of the 20 segments, 3 were in bad condition, 10 were in fair condition, 5 were in good condition, and 2 were in very good condition. The majority road problem was happened in hot places in terms of rutting (SIGAR, 2016). Extensive research may need to be conducted to determine the reasons of road poor prefromance in Afghansitan. The results of studies show that local design inputs like temperature may has high impact on flexible pavement performance which is not well considered by AASHTO 1993.

Therefore, this study investigated the temperature effect on flexible pavement distresses in hot and cold regions in Afghanistan to determine whether the designed pavements using AASHTO 1993 is optimized or not.

\section{Methodology}

To achieve the objective of the study, a typical three-layer flexible pavement (AC layer, granular base layer, and subbase layer) was designed using AASHTO 1993 for three traffic levels $(5,20$, and 50 ESAL) and for three subgrade types $(5,10$, and $20 \mathrm{CBR})$ at $85 \%$ reliability level for 20 -year design life (See Table 1). Then, the pavement performances such as rutting and alligator cracking were predicted using the $\mathrm{ME}$ pavement design method software (3d Move Analysis). The 3d Move Analysis software was run once for every pavement structure, the run time is approximately 15 minutes. The predicted pavement performances were compared to performances threshold values to check the pavement failure conditions. In this study, the ME pavement design method default threshold values were used because pavement performance threshold values have not yet been determined in Afghanistan. According the ME pavement design method, all predicted pavement performances should be kept bellow than threshold values otherwise the pavement would be faced to premature failure, which is not acceptable. The recommended performance threshold values are shown in Table 1.

Table 1

Recommended Performance Threshold Values (AASHTO, 2008)

\begin{tabular}{|l|c|c|}
\hline Performance Types & $\begin{array}{c}\text { Performance } \\
\text { Limit Values }\end{array}$ & $\begin{array}{c}\text { Reliability } \\
\%\end{array}$ \\
\hline AC rutting (mm) & 10 & 85 \\
\hline Total rutting, in (mm) & 20 & 85 \\
\hline Alligator cracking (\%) & 25 & 85 \\
\hline
\end{tabular}




\subsection{Design Inputs for AASHTO 1993}

The design inputs for the designing of typical pavement structures (AC surface, granular base, and subbase) were extracted from the AASHTO 1993 [9]. The design was done for three traffic levels such as 5 million, 20 million, 50 million ESAL, three-subgrade type like 5, 10, and $20 \mathrm{CBR}$ at $85 \%$ reliability and 20 -year design life. The whole design inputs were illustrated in Table 2 .

Table 2

Design Inputs for AASHTO 1993

\begin{tabular}{|l|c|}
\hline Design Input & $\begin{array}{c}\text { Values for all } \\
\text { Traffic Levels }\end{array}$ \\
\hline Initial service ability, $P_{0}$ & 4.2 \\
\hline Terminal serviceably, $P_{t}$ & 2.5 \\
\hline Reliability $(\%)$ & 85 \\
\hline Overall standard deviation, $S_{0}$ & 0.45 \\
\hline Design life, Years & 20 \\
\hline Resilient modulus of base, MPa & 207 \\
\hline Resilient modulus of subbase, MPa & 100 \\
\hline Subgrade CBR, \% & $5,10,20$ \\
\hline AC Layer coefficient, $a_{1}$ & 0.42 \\
\hline Base Layer coefficient, $a_{2}$ & 0.14 \\
\hline Subbase Layer coefficient, $a_{3}$ & 0.11 \\
\hline Drainage coefficient, $m_{2}$ & 1 \\
\hline Drainage coefficient, $m_{3}$ & 1 \\
\hline
\end{tabular}

Source: (AASHTO, 1993)

\subsection{Design Inputs for ME Pavement Design}

Detailed design inputs such as material properties (AC dynamic modulus, poison's ration, aggregate gradation, binder grade, air void, and effective binder content etc.), traffic characteristics (Average annual daily truck traffic, truck classification, truck distribution, traffic growth factor, axle distribution factor, axle number, traffic monthly and hourly distribution), and climate data are required by MEPDG and its software to calculate pavement responses (stresses and strain) and predict pavement distresses like fatigue cracking, thermal cracking, and rutting as well as international roughness index (IRI).

\subsubsection{Material Inputs}

The design inputs like asphalt penetration grade, effective binder content, air voids, poison's ration, aggregate gradation which are used in this study are shown in Table 3 and Table 4. 


\section{Table 3}

Hot-Mixed Asphalt Mixture Properties

\begin{tabular}{|l|c|}
\hline Inputs & Values \\
\hline Penetration grade, $(0.1 \mathrm{~mm})$ & $60 / 70$ \\
\hline Effective binder content Vbe (\%) & 8 \\
\hline Air voids Va (\%) & 6 \\
\hline AC poison's ratio & 0.3 \\
\hline AC resilient modulus, Mpa & 8600 \\
\hline
\end{tabular}

\section{Table 4}

Hot-mixed Asphalt Mixture Aggregate Gradation

\begin{tabular}{|l|c|}
\hline Inputs & Values \\
\hline$\%$ passing the sieve $19 \mathrm{~mm}$ & 100 \\
\hline$\%$ passing the sieve $9.5 \mathrm{~mm}$ & 80 \\
\hline$\%$ passing the sieve $4.75 \mathrm{~mm}$ & 45 \\
\hline$\%$ passing the sieve $0.075 \mathrm{~mm}$ & 5 \\
\hline
\end{tabular}

\subsubsection{Prediction of Dynamic Modulus}

In design inputs level 3, ME pavement design method uses Witczak equation to predict the HMA dynamic modulus Eq. (1), (NCHRP, 2004).

$$
\begin{aligned}
& \log \left(E^{*}\right)=3.750063+0.02932 \rho_{200}-0.001767\left(\rho_{200}\right)^{2} \\
& -0.002841 \rho_{4}-0.05809 V_{a}-0.802208\left(\frac{V_{b e f f}}{V_{b e f f}+V_{a}}\right) \\
& +\frac{3.871977-0.0021 \rho_{4}+0.003958 \rho_{38}-0.000017\left(\rho_{38}\right)^{2}+0.005470 \rho_{34}}{1+e^{(-0.603313-0.313351 \log (f)-0.393532 \log (\eta))}}
\end{aligned}
$$

Where: $E^{*}$ - dynamic modulus of mix, 105 psi; $\eta$ - viscosity of binder, 106 poise; $f$ - loading frequency $(\mathrm{Hz}) ; \rho_{200}-\%$ passing the $0.075 \mathrm{~mm}$ sieve; $\rho_{4}$ - \% retained on $4.75 \mathrm{~mm}$ sieve; $\rho_{38}$ - \% retained on $9.5 \mathrm{~mm}$ sieve; $\rho_{34}$ - \% retained on $19 \mathrm{~mm}$ sieve; $\mathrm{V}_{\mathrm{a}}$ - air void, \% by volume; $\mathrm{V}_{\text {beff }}$ - effective binder content, \%;

\subsubsection{Temperature Inputs}

The monthly average temperature data for selected zones (Kandahar and Bamiyan) have been extracted from World Weather Online (See Table 5) [9]. The pavement temperature is required by
3D Move Analysis, therefore, monthly average air temperature was changed to annual average air temperature, and then pavement temperature was calculated using Eq. (2), (Thompson et al., 1987). The calculated pavement temperature is shown in Table 6. 


\section{Table 5}

Average Monthly Temperature

\begin{tabular}{|l|c|c|}
\hline \multicolumn{1}{|c|}{ Months } & $\begin{array}{c}\text { Bamiyan } \\
\left({ }^{\circ} \mathbf{C}\right)\end{array}$ & $\begin{array}{c}\text { Kandahar } \\
\left({ }^{\circ} \mathbf{C}\right)\end{array}$ \\
\hline January & -7.70 & 6.10 \\
\hline February & -6.10 & 8.30 \\
\hline March & -0.40 & 13.60 \\
\hline April & 5.30 & 20.00 \\
\hline May & 9.80 & 25.80 \\
\hline June & 13.80 & 30.00 \\
\hline July & 16.10 & 31.70 \\
\hline August & 15.30 & 29.90 \\
\hline September & 11.50 & 25.20 \\
\hline October & 6.10 & 19.10 \\
\hline November & 1.00 & 13.10 \\
\hline December & -4.20 & 8.10 \\
\hline
\end{tabular}

$T_{P}=T_{A}\left(1+\frac{1}{Z+4}\right)-\frac{34}{Z+4}+6$

Where: $\mathrm{T}_{\mathrm{P}}$ - average seasonal pavement temperature $\left({ }^{\circ} \mathrm{F}\right) ; \mathrm{T}_{\mathrm{A}}$ - average seasonal air temperature $\left({ }^{\circ} \mathrm{F}\right) ; \mathrm{Z}$ - depth at which temperature is predicted (in).

\section{Table 6}

Average Monthly and Pavement Temperature

\begin{tabular}{|l|c|c|}
\hline Study Zones & $\begin{array}{c}\text { Annual average air } \\
\text { Temperature }\left({ }^{\circ} \mathbf{C}\right)\end{array}$ & $\begin{array}{c}\text { Pavement Temperature } \\
\left({ }^{\circ} \mathbf{C}\right)\end{array}$ \\
\hline Kandahar & 19.24 & 25 \\
\hline Bamiyan & 5.04 & 8.89 \\
\hline
\end{tabular}

\subsubsection{Pavement Structure Inputs}

The designed pavement structure using AASHTO were used in MEPDG Software
(3D Move Analysis) to predict the pavement performances (rutting and alligator cracking) for 20 -year design life at $85 \%$ reliability (Table 7 ).

\section{Table 7}

Pavement Structure

\begin{tabular}{|l|c|c|c|}
\hline \multirow{2}{*}{ Layer } & \multicolumn{3}{|c|}{$\begin{array}{c}\text { Traffic Volume } \\
\text { (ESAL in millions) }\end{array}$} \\
\cline { 2 - 4 } & $\mathbf{5}$ & $\mathbf{2 0}$ & $\mathbf{5 0}$ \\
\hline AC layer $(\mathrm{mm})$ & 157 & 196 & 226 \\
\hline Base layer $(\mathrm{mm})$ & 152 & 178 & 193 \\
\hline Subbase layer $(\mathrm{mm})$ & 230 & 254 & 274 \\
\hline
\end{tabular}




\subsection{D-Move Analysis Software}

“The 3D-Move Analysis software can account for important pavement response factors such as the moving traffic-induced complex $3 \mathrm{D}$ contact stress distributions (normal and shear) of any shape, vehicle speed, and viscoelastic material characterization for the pavement layers. This approach treats each pavement layer as a continuum and uses the Fourier transform technique; therefore, it can handle complex surface loadings such as multiple loads and non-uniform tire pavement contact stress distribution. This software calculates pavement responses (stress and strain) and predicts various pavement distress such AC, base, subbase and subgrade rutting, alligator and top-down cracking. It was developed by University of Nevada Reno (UNR) based on the National Cooperative Highway Research Program (NCHRP) project 1-37A and Mechanistic-Empirical Pavement Design Guide"(ARC, 2013). See Fig. 1.

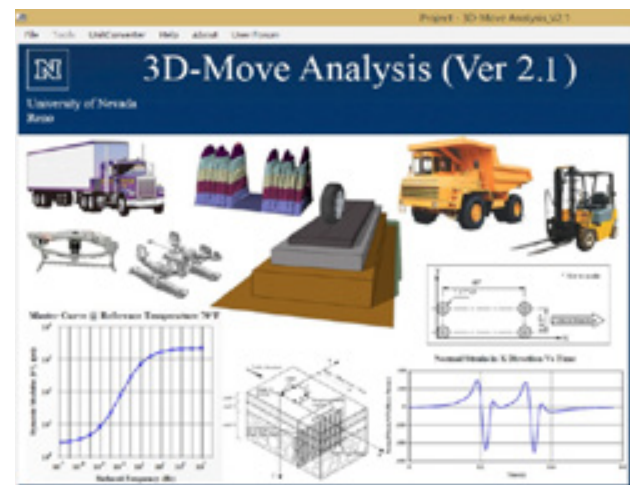

Fig. 1.

Screenshot of Selected Research Program

Source: (ARC, 2013)

\section{Results and Discussions}

The pavement structure analysis and design were done at $85 \%$ reliability for 20 -year design life.

The predicted pavement performances were compared with threshold values at the end of design life to determine the impact of temperature on flexible pavement performance.

\subsection{Impact of Temperature on alligator Cracking}

Analysis results show that alligator cracking is not affected by temperature variation. Subgrade type and traffic levels effect on alligator cracks that for a decrease in traffic level and an increase in subgrade strength, alligator cracking decreases. It is applicable for all traffic levels and any subgrade type (See Fig. 2). 


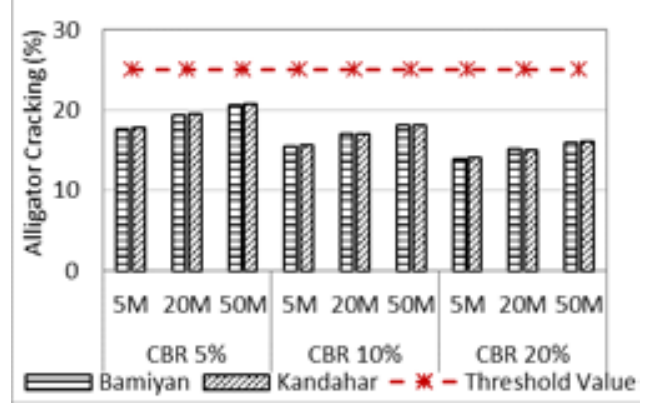

Fig. 2.

Alligator Cracking

\subsection{Impact of Temperature on AC Rutting}

Analysis results showed that asphalt concrete $(A C)$ rutting is sensitive to traffic level, subgrade type, and extremely sensitive to temperature variations. The AC rutting is increased when traffic level and subgrade strength increase. The study results show that there is a big difference in AC magnitude between Bamiyan and Kandahar for the same traffic level and subgrade type. In the hot region, the AC rutting depth is significantly high, and it is exceeded from the threshold value for 20 and 50 million ESAL at the end of the design life. Also, the analysis result shows that in the cold region, AC rutting is not a big problem for flexible pavement. For high traffic levels (50 million ESAL), the AC rutting depth is exceeded from the threshold value, but this passing is minor, which can be neglected (See Fig. 3).

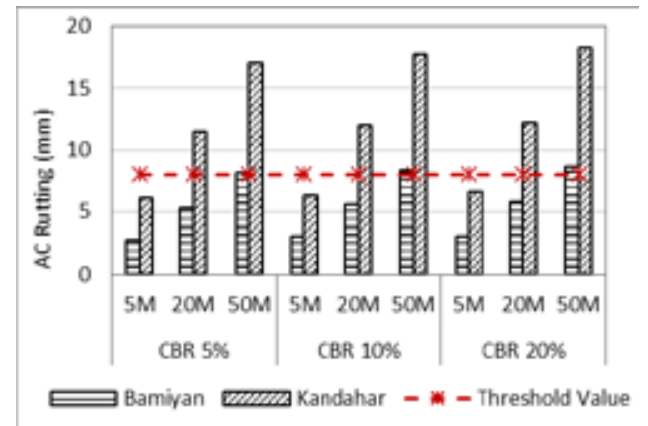

Fig. 3.

AC Rutting

\subsection{Impact of Temperature on Total Rutting}

According to analysis results, total rutting is also highly sensitive to pavement temperature and traffic volume. In cold region (Bamiyan) for any traffic level total rutting is lower than threshold value. But in in Kandahar for 50 million ESALD total rutting depth is higher than threshold value. 
It is also resulted that an increase in traffic level results higher total rutting magnitude on the flexible pavement (See Fig. 4). Figures number 3 and 4 show that pavement would be faced to premature failure in terms of AC and total rutting in hot region. It means that AASHTO 1993 under-designs the pavement structure.

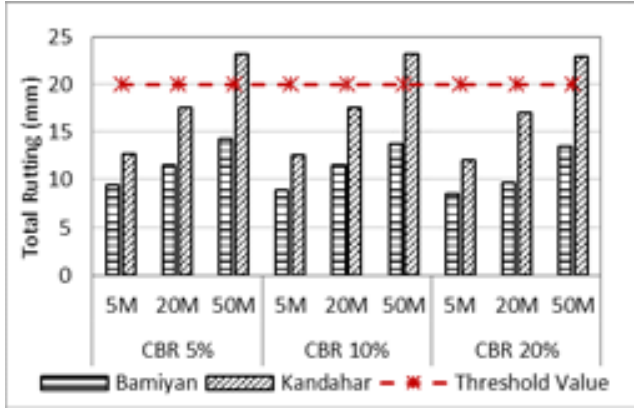

Fig. 4.

Total Rutting

\subsection{Optimal Pavement Design}

Based on analysis results, the flexible pavement structure designed using AASHTO 1993 would be faced with premature failure in terms of $\mathrm{AC}$ and total rutting. The literature shows that using a stiffer grade of binder, decreasing in-place air voids, and binder content would improve the pavement performance interim of the rutting (Shakhan et al., 2021). To keep the AC and total rutting depth bellow threshold values for medium and high traffic levels (20 and 50 million ESAL) in Kandahar: At first, air voids decreased from 6 to $4 \%$, and effective binder content reduced from 8 to $6 \%$, and secondly, HMA layer thickness was increased, and analysis was done for two traffic levels and three subgrade types. The thickness of the HMA layer was increased until that predicted $\mathrm{AC}$ and total rutting are become lower than threshold values. Optimized pavement structure is shown in Fig. 5 and Table 8.

Fig. 5.

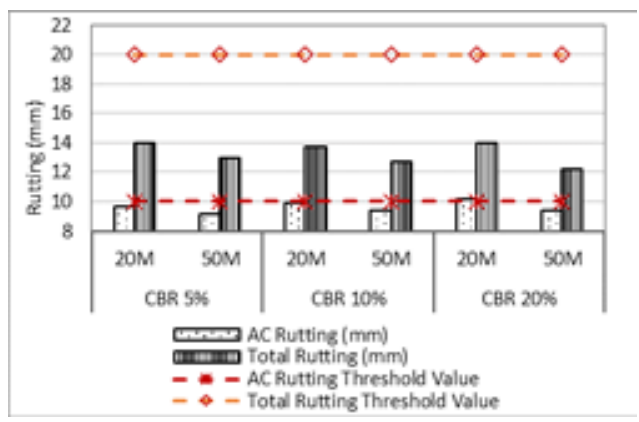

Total and AC Rutting 
Table 8

Optimized Pavement Structure

\begin{tabular}{|l|c|c|c|}
\hline \multirow{2}{*}{ Layer } & \multicolumn{3}{|c|}{$\begin{array}{c}\text { Traffic Volume } \\
\text { (ESAL in millions) }\end{array}$} \\
\cline { 2 - 4 } & $\mathbf{5}$ & $\mathbf{2 0}$ & $\mathbf{5 0}$ \\
\hline AC surface $(\mathrm{mm})$ & 157 & 279 & 343 \\
\hline Base $(\mathrm{mm})$ & 152 & 178 & 193 \\
\hline Subbase $(\mathrm{mm})$ & 230 & 254 & 274 \\
\hline
\end{tabular}

Figure 4 shows that increasing HMA layer thickness, using lower air voids, and binder content result to lower $\mathrm{AC}$ and total rutting magnitude. Also, figure 4 shows that an increase in HMA layer thickness leads to a significant reduction in total rutting than AC rutting. This happens because increase HMA layer leads to lower subgrade rutting. By looking at HMA layers thickness in tables 7 and 8 , also in figures 3, 4, and 5, to keep $\mathrm{AC}$ and total rutting bellow threshold values for high traffic levels in Kandahar, a 1.5 scale factor is needed to be multiplied to HMA layer thickness designed by AASHTO 1993 method.

\section{Conclusion and Recommendations}

Environmental effects appear as cracking and permanent deformation in a flexible pavement. The advantage of the ME pavement design method is that consider the climate conditions in pavement design. Based on objective of this study, the temperature impact on pavement performance was investigated for hot and cold regions (Kandahar and Bamiyan) in Afghanistan. The study results are summarized as follows:

- The alligator cracking in flexible pavement is not sensitive to air temperature variation but sensitive to traffic levels and subgrade strength. The pavement structure which were designed using AASHTO 1993 shows a good performance in term of alligator cracking;
- The AC permanent deformation is extremely sensitive to temperature variations, traffic levels and subgrade types. The AC rutting depth exceeds from threshold value for medium and high traffic levels in hot zone, which is reflected the prevalent rutting problem in Kandahar. In the same climate condition, the AC rutting changes by variation in traffic level and subgrade type, higher traffic level and stiffer subgrade lead to higher permanent deformation;

- Total rutting is sensitive to temperature, subgrade type, and traffic levels, higher temperature, higher traffic levels, and lower subgrade leads to higher total rutting.

The AASHTO 1993 designs thinner pavement layers for high traffic levels in hot region, therefore, a 1.5 scale factor needs to be used to scale up the pavement thickness.

\section{References}

AASHTO. 1993. Guide for Design of Pavement Structures. American Association of State Highway and Transportation Officials, Washington, D.C. USA. 624 p.

AASHTO. 2008. Mechanistic Empirical Pavement Design Guide: A Manual of Practice. Interim Ed. USA: American Association of State Highway and Transportation Officials. 218 p. 
AASHTO. 2020. Mechanistic-Empirical Pavement Design Guide: A Manual of Practice. 3rd ed. USA: American Association of State Highway and Transportation Officials. 264 p.

Amini, A.A.; Behbahani, H. 2011. Comparison of Pavement Design using AASHTO 1993 and NCHRP Mechanistic-Empirical Pavement Design Guides. In Proceedings of the 5th International Conference Bituminous Mixtures and Pavements, 1-10.

ARC. 2013. Pavement Response Model to Dynamic Loads 3D Move. Quarterly Technical Progress Report. Asphalt Research Consortium. USA.

Carvalho, R.L.; Schwartz, C.W. 2006. Comparisons of Flexible Pavement Designs: AASHTO Empirical Versus NCHRP project 1-37A Mechanistic-Empirical, Transportation Research Record 1947(1): 167-174.

El-Badawy, S.M.; Bayomy, F.M.; Santi, M.; Clawson, C.E. 2011. Comparison of Idaho Pavement Design Procedure with AASHTO 1993 and MEPDG Methods. In Proceedings of the Transportation and Development Institute Congress:Integrated Transportation and Development for a Better Tomorrow, 586-595.

El-Shaib, M.A.; El-Badawy, S.M.; Shawali, E.S.A. 2017. Comparison of AASHTO 1993 and MEPDG Considering the Egyptian Climatic Conditions, Innovative Infrastructure Solutions 2(18): 2-9.

Mulandi, J.; Khanum, T.; Hossain, M.; Schieber, G. 2006. Comparison of Pavement Design Using AASHTO 1993 and NCHRP Mechanistic-Empirical Pavement Design Guides. In Proceedings of the Airfield and Highway Pavement Specialty Conference, 912-923.
NCHRP. 2004. Guide for Mechanistic-Empirical Design of New and Rehabilitated Pavement Structures, Part 1. Itroduction. National Cooperative Highway Research Program, Illinois. USA.

Saha, J.; Nassiri, S.; Bayat, A.; Soleymani, H. 2014. Evaluation of the Effects of Canadian Climate Conditions on the MEPDG Predictions For Flexible Pavement Performance, International Journal of Pavement Engineering 15(5): 392-401.

Shakhan, M.R.; Topal, A.; Şengöz, B.; Almusawi, A. 2019. Review of the Implementation of the MechanisticEmpirical Pavement Design Guide. In Proceedings of the $3^{\text {rd }}$ International Students Science Congress, 138-153.

Shakhan, M.R.; Topal, A.; Sengoz, B.; Ozturk, H.I. 2021. The Predicted Impact of Design Parameters in Asphalt Concrete Layers on Pavement Performance, Proceedings of the Institution of Civil Engineers - Transport 174(6): 1-18.

SIGAR. 2016. Special Inspector General for Afghanistan Reconstruction (SIGAR), 2016. Special Inspector General for Kabul.

Thompson, M.R.; Dempsey, B.J.; Hill, H.; Vogel, J. 1987. Characterizing Temperature Effects for Pavement Analysis and Design, Transportation Research Record 12(8): 14-22. 